\title{
BMJ Open Identification of factors associated with resilience in medical students through a cross-sectional census
}

\author{
Anna Christina Pinho de Oliveira, ${ }^{1}$ André Paes Goulart Machado, ${ }^{2}$ \\ Renata Nunes Aranha ${ }^{3}$
}

To cite: Oliveira ACPde, Machado APG, Aranha RN. Identification of factors associated with resilience in medical students through a cross-sectional census. BMJ Open 2017;7:e017189. doi:10.1136/ bmjopen-2017-017189

- Prepublication history for this paper is available online. To view these files please visit the journal online (http://dx.doi. org/10.1136/bmjopen-2017017189).

Received 11 April 2017

Revised 9 August 2017

Accepted 27 September 2017

\section{CrossMark}

${ }^{1}$ Internal Medicine, Division of Pulmonary Medicina, Universidade Federal Fluminense, Niteroi, Rio de Janeiro, Brazil

${ }^{2}$ Internal Medicine, Universidade Estadual do Rio de Janeiro, Rio de Janeiro, Rio de Janeiro, Brazil ${ }^{3}$ Public Health, Universidade Estadual do Rio de Janeiro, Rio de Janeiro, Rio de Janeiro, Brazil

Correspondence to Associate Professor Anna Christina Pinho de Oliveira Miss; pinho.christina64@gmail.com

\section{ABSTRACT}

Objectives Research on resilience has been gaining momentum, and it has already been shown that increased resilience creates positive changes at the individual and collective levels. Understanding of the factors associated with resilience may guide specific actions directed towards different populations. The objective of this study was to investigate these associated factors within a population of medical students.

Design Cross-sectional census.

Setting A public medical school in the state of Rio de Janeiro, Brazil.

Participants Out of a total of 551 medical students, five students were excluded due to inactive registrations, and four transferred students were also excluded, resulting in a total of 542 remaining participants.

Measures Adopting an anonymous questionnaire that included the Resilience Scale, in addition to questions related to sociodemographic, behavioural health-related and academic variables, the association between these variables and resilience was investigated.

Results The high rate of answers to each item constitutes a indication of students' interest in participating, whereas the lowest percentile was $97.1 \%$. The mean resilience score obtained was considered moderate. Factors such as gender, race, previous schools attended, financial independence, living situation, parents' education level, religion, quota-based admission, smoking, alcohol abuse and use of illegal drugs were not associated with resilience. In a multivariate analysis using ordinal logistic regression, associations were maintained only between the highest resilience score and the non-use of habitforming prescription drugs (OR: $0.58 ; 95 \% \mathrm{Cl} 0.41$ to $0.80)$, having a better perception of one's own health (OR: $0.57 ; 95 \% \mathrm{Cl} 0.41$ to 0.81 ) and being older (OR: $1.37 ; 95 \%$ Cl 1.12 to 1.67$)$.

Conclusion The census performed with the medical students showed, with the multivariate analysis, that besides age, the variables most closely tied with resilience were health and medicalisation, and the variables connected with income and religion showed no association.

\section{INTRODUCTION}

All people are subject to negative situations and, often times, the causes cannot be controlled. Learning how to cope with such

\section{Strengths and limitations of this study}

- This study compares the factors associated with resilience in medical students and so compares them with other populations that have been already studied.

- Design strengths of the study: it is a census, using a Resilience Scale, a tool used in different populations and valid for Portuguese, instead of indirect assessments commonly used with this kind of population. The questionnaire was anonymous. The intention here was to improve the accuracy of the most delicate questions.

- The limitations include: the cross-sectional design of the study does not allow the establishment of a temporal relation between exposure to situations of distress and its effects on medical students.

situations may reduce the damage they cause and increase one's ability to address daily challenges. So, one way to improve the ability to cope with undesirable situations is to increase individual resilience.

Resilience is defined as a person's ability to, in different degrees, when exposed to negative experiences, recover and, even, grow as a result of the adversity experienced, ${ }^{1-5}$ by way of a positive psychosocial adaptation to the experience. This understanding, which before was nearly restricted to children, ${ }^{67}$ is now being applied in many different scenarios, such as the corporate world, ${ }^{8}$ health, ${ }^{9}$ education ${ }^{10}$ and the communities, ${ }^{11}$ and is expanding day by day.

Previous studies have indicated a number of factors capable of affecting individual resilience. Among the factors that might increase resilience is time spent with loving and sensitive parents, ${ }^{3}$ peer support, ${ }^{12}$ taking time out for oneself ${ }^{13}$ and professional stability. ${ }^{14} 15$ In contrast, among the factors capable of reducing one's resilience are the lack of affection during childhood or youth, ${ }^{16} 17$ sleep disorders ${ }^{12}$ or unemployment. ${ }^{18}$ Most relevant studies have shown that 
the level of education, ${ }^{19}$ income $e^{20}$ and $\operatorname{sex}^{101621}$ do not impact resilience.

Understanding the factors that can increase individual or collective resilience is important because of the benefits that this understanding can bring, such as: increased well-being and improved quality of life, ${ }^{3}{ }^{22}$ reduced chances of engaging in prostitution ${ }^{23}$ and violent behaviour, ${ }^{2425}$ reduced tobacco use ${ }^{23}$ and drug use, ${ }^{23}$ and lessened depression and suicidal thoughts. ${ }^{186}$ Resilience is also associated with the greater tolerance to work-related stress, ${ }^{27}$ an increased ability to cope with chronic pain, ${ }^{28}$ and ageing with fewer limitations and higher cognitive levels. ${ }^{18}$

These findings, associating resilience to a number of different variables, were reached through studies conducted in several countries, among highly diversified groups, although in many of these studies, resilience was not measured using a specific scale. There is an understanding today that medical school might, for a number of reasons ${ }^{29-31}$ expose the student to different forms of suffering, ${ }^{29} 3233$ while increased resilience can help minimise this, in addition to affording other gains to this specific population. ${ }^{3435}$ In light of this, this study proposes to apply the Wagnild and Young Resilience Scale ${ }^{36}$ to a census performed among medical students, to measure and understand the associations between resilience and sociodemographic, behavioural health-related and academic variables within this group.

\section{METHODOLOGY}

This article describes a cross-sectional study conducted through the performance of a census, from October to December 2011. The sample population included all of the 551 students of a public medical school in Rio de Janeiro, Brazil, excluding five students whose enrolment was inactive at the time and four others who had transferred into the course. So, a total of 542 students remained. A self-administered questionnaire was prepared, addressing several aspects (sociodemographic, academic and health behaviour), in addition to the Resilience Scale. The sociodemographic variables included sex, race, age, course year, prior schools, financial independence, living situation, living situation, parents' education level, religion and whether the respondent was a quota-admitted student (admission to the university as a result of a quota system).

The behavioural health-related aspects included a perception of the student's own health, smoking habits, use of habit-forming medications (sleeping pills, staying awake and anxiety), use of illegal drugs (marijuana, cocaine and crack) and alcohol. In addition, the Cut down, Annoyed by criticism, Guilty, Eye-opener (CAGE) questionnaire was used, which has the purpose of identifying individuals suspected of abusing alcohol, when the respondents answer two or three of its four questions affirmatively. ${ }^{37}$ In this study, two affirmative answers in the CAGE rendered the test positive.
The variable of primary interest was measured using the Wagnild and Young Resilience Scale, ${ }^{36}$ which has been translated into Portuguese and cross-culturally adapted for use in Brazil. ${ }^{38}$ The scale consists of 25 positively described items. The answers are quantified based on a Likert scale, with values ranging from 1 to 7 , where 1 means 'I completely disagree' and 7 means 'I completely agree'. So, the final scores can vary between 25 and 175 points. To measure resilience levels, Wagnild ${ }^{39}$ proposed the following score ranges: very low (25-100), low (101$115)$, on the low end (116-130), moderate (131-145), moderately high (146-160) and high (161-175). In this study, these score ranges were regrouped into three categories: low (25-130), moderate (131-145) and high (146-175).

A preliminary test was conducted with 12 volunteers with social and functional profiles similar to those of the sample population. In compliance with institutional and legal requirements, all the participants in the census were informed of the study's purposes and stages, its voluntary nature, the confidentiality of the data and the lack of associated risks. It was only after the student signed the informed consent form that he or she completed the questionnaire, which was presented online, in a clear and user-friendly form, with the Qualtrics software, on computers made available during flexible hours, in comfortable rooms, at the Medical School. The students were invited to participate in the study by email and encouraged to participate via additional emails, online social networks and considerable personal involvement of the researchers and class representatives. No pressure was made, nor was any reward offered for the students' participation in the study.

Central trend measurements, proportions and frequency distributions were used for the descriptive analysis of the sample population. The main variable (resilience score) was evaluated in the continuous and categorical forms. The categorical variables were analysed using the $\chi^{2}$ test, whereby a $p$ value of $<0.05$ was considered statistically significant. The OR and its $95 \%$ CI were estimated using logistic regression to compare high with low resilience and moderate with low resilience. The statistical software program Stata V.11.0 was used.

Ordinal logistic regression was used for the subsequent multivariate analysis. All the variables that presented a $p$ value of $\leq 0.20$ in the $\chi^{2}$ test were incorporated into the model. So, initially, the following variables were selected: age, parents' education level, year in the programme, perception of one's own health, alcohol use, CAGE result and use of medications. The Brant test was used to evaluate the preassumption fit of the logistic ordinal model, that is to say, to test whether the relationship between each pair in the outcome groups was always the same. Each variable was introduced individually to determine if it would remain in the model considering the change caused in the $\log$-likelihood and the pseudo $\mathrm{R}^{2}$ values. The Besley Test was performed to test for collinearity between certain variables. 
Table 1 Distribution of resilience scores by category

\begin{tabular}{llllllll}
\hline & N & Median & Mean & SD & Minimum & Maximum \\
\hline Low & 203 & 120 & 117 & 11.6 & 70 & 130 & 145 \\
Moderate & 212 & 138 & 138 & 4.3 & 131 & 146 & 171 \\
\hline High & 127 & 149 & 151 & 5.8 & 145 \\
\hline
\end{tabular}

\section{RESULTS}

All 542 students in the study population participated in the survey. Of those students, 328 were female (60\%) and 214 were male $(40 \%)$. Ninety-five per cent of the participants ranged between the ages of 17 and 30 years. The authors believe that the high rate of answers to each item constitutes a clear indication of the real interest in participating, whereas the lowest percentile was $97.1 \%$ (for the variable concerning the use of illegal drugs), that is to say, even in anonymity, the participation was considered good. Female participation predominated, with 328 students $(60 \%)$.

The mean resilience score was 133.4 points, with a SD of 15.8. In the stratification using the resilience score ranges, the following was noted: in the low category, mean score of $120(\mathrm{SD}=11.6)$; in the moderate category, mean score of $138(\mathrm{SD}=4.3)$; and in the high category, mean score of $151(\mathrm{SD}=5.8)$ (table 1$)$.

No significant association was found between resilience and nearly all social economic variables (prior schools, financial independence, parents' education level and quota-based admission). Likewise, no association was found between resilience and religion, gender, race or living situation.

Regarding the variable of age, the older that the individual was, the greater his or her resilience. Among younger students (younger than 22 years), only $15 \%$ showed high resilience; in contrast, among students older than 22 years, the percentage displaying high resilience was approximately $28 \%$. The bivariate analysis indicated increased resilience with age. When moderate resilience was compared with low resilience among older participants (22-24 years) as compared with younger participants (17-22 years), the OR was 1.8 (95\% CI 1.1 to 2.8), and when high resilience and low resilience were compared, the OR was higher, namely: 2.9 (95\% CI 1.6 to 5.1) (table 2).

Resilience was associated with perception of one's own health $(p=0.00)$. Students with very good perception in that area more often showed high resilience than those with regular or poor perception $(35.1 \%$ vs $9.8 \%)$. In addition, the following relation was observed: the better the perception of one's own health, the higher the person's resilience, up to a sevenfold difference in the resilience score between the extremes.

A higher number of students with low resilience $(55.7 \%)$ were found among the participants who use or have used habit-forming medications, as compared with the participants who have never used said medications $(34.3 \%)$. Smoking and illegal drug use showed no association with resilience. Students who presented a positive CAGE result showed higher rates of low resilience $(50 \%)$ than those with a negative result (35\%), with an OR of 0.5 (95\% CI 0.3 to 0.9 ) (table 3 ).

Only the variables that were significant were retained in the multivariate analysis. The year in the programme and age were significant variables, when introduced separately. However, when introduced in the model together, neither proved significant, which indicates a likely collinearity in the model, although the collinearity between the two variables was not very high (Besley Test of Collinearity=6.49).

The multivariate analysis in table 4 shows the result of a parsimonious model, which has greater explanatory power, consisting only of the variables with statistical significance following control-perception of one's own health, age and use of medications - showing the adjusted ORs and the respective CIs.

The model showed statistical significance ( $\mathrm{p}$ value of the $\left.\log \chi^{2}<0.05\right)$, although the pseudo- ${ }^{2}$ was low $(0.05)$. The Brant test result was not significant $(\mathrm{p}=0.54)$, which indicates that there was no difference in the coefficient among the pairs, proving that this type of analysis is appropriate for this study. In this analysis, the variables of use of habit-forming medications (OR: 0.58; 95\% CI 0.41 to 0.80 ), the perception of one's own health (OR: 0.57 ; 95\% CI 0.41 to 0.81 ) and age (OR: $1.37 ; 95 \%$ CI 1.12 to 1.67) maintained their association with resilience.

\section{DISCUSSION}

The evaluation of the medical students showed a group with moderate resilience, with a mean score of 133.4 points on the Resilience Scale. In published studies involving other groups, such as middle-aged Spanish women, ${ }^{18}$ street children and youngsters in Ghana ${ }^{23}$ and health professionals in the $\mathrm{UK}^{40}$ a pattern of resilience similar to that of the group under study was found, despite the use of other scales considered more relevant by the researchers.

In contrast, other groups have shown higher than moderate resilience: a group of elderly individuals in the USA showed moderately high resilience, ${ }^{41}$ a randomly selected Swedish population displayed high resilience ${ }^{42}$ and a study conducted among medical students in the USA showed the majority to have moderately high resilience. ${ }^{43}$ Despite the diversity of countries and populational characteristics represented by these studies, a certain consistency was found in the mean resilience, as neither of them produced extreme values. 
Table 2 Proportions and ORs with Cls for the sociodemographic variables according to the resilience levels

\begin{tabular}{|c|c|c|c|c|c|c|}
\hline & \multicolumn{3}{|c|}{ Resilience } & \multirow[b]{2}{*}{ \%high } & \multirow{2}{*}{$\begin{array}{l}\text { Moderate resilience } \\
\text { OR }(95 \% \mathrm{Cl})\end{array}$} & \multirow{2}{*}{$\begin{array}{l}\text { High resilience } \\
\text { OR }(95 \% \mathrm{CI})\end{array}$} \\
\hline & $\mathbf{N}$ & \%low & $\%$ moderate & & & \\
\hline \multicolumn{7}{|l|}{ Sex } \\
\hline Female & 328 & 36.3 & 39 & 24.7 & $1.1(0.7-1.6)$ & $1.2(0.8-2.0)$ \\
\hline \multicolumn{7}{|l|}{ Race } \\
\hline Mixed race & 139 & 38.1 & 41 & 20.9 & $1.1(0.7-1.7)$ & $0.9(0.4-2.0)$ \\
\hline Black & 57 & 37.9 & 38.5 & 23.6 & $1.2(0.6-2.2)$ & $1.0(0.4-2.0)$ \\
\hline \multicolumn{7}{|l|}{$\mathrm{Age}^{\star}$} \\
\hline First tertile (17-22 years) & 181 & 48.1 & 36.5 & 15.4 & & \\
\hline Private & 280 & 33.3 & 43.3 & 23.4 & & \\
\hline Both & 116 & 33.6 & 37.9 & 28.5 & $1.2(0.7-2.1)$ & $1.6(0.9-2.8)$ \\
\hline Public & 141 & 41.4 & 37.1 & 21.5 & $1.4(0.7-2.3)$ & $1.3(0.8-2.3)$ \\
\hline \multicolumn{7}{|l|}{ Financial independence } \\
\hline No & 377 & 38.5 & 39.5 & 22 & & \\
\hline Yes & 162 & 35.2 & 37.6 & 27.2 & $1.0(0.7-1.6)$ & $1.3(0.8-2.2)$ \\
\hline \multicolumn{7}{|l|}{ Lives with } \\
\hline Father and/or mother & 330 & 36.7 & 40.9 & 22.4 & & \\
\hline Secondary & 141 & 30.5 & 43.3 & 26.2 & $1.5(0.7-3.0)$ & $1.0(0.5-2.2)$ \\
\hline Higher & 334 & 41 & 37.7 & 21.3 & $1.0(0.5-1.8)$ & $0.6(0.3-1.2)$ \\
\hline \multicolumn{7}{|l|}{ Religion } \\
\hline No religion & 126 & 36.5 & 45.2 & 18.3 & & \\
\hline Catholic & 210 & 35.2 & 38.1 & 26.7 & $0.9(0.5-1.4)$ & $1.5(0.8-2.8)$ \\
\hline Protestant & 98 & 42.9 & 34.7 & 22.4 & $0.6(0.3-1.2)$ & $1.0(0.5-2.1)$ \\
\hline Spiritualist & 86 & 43 & 36.1 & 20.9 & $0.7(0.4-1.2)$ & $1.0(0.4-2.1)$ \\
\hline \multicolumn{7}{|l|}{ Quota student } \\
\hline No & 290 & 39.7 & 39.3 & 21 & & \\
\hline Yes & 252 & 34.9 & 38.9 & 26.2 & $1.1(0.8-1.7)$ & $1.4(0.9-2.2)$ \\
\hline
\end{tabular}

Reference category: low resilience.

${ }^{*} \mathrm{p}$ Value $<0.2$.

This study chose medical students as its sample population. There is a consensus today that medical school is a source of psychological suffering due to the ongoing exposure to stress factors, such as the broad curriculum, concern about the future, parents' high expectations, ${ }^{38}$ concerns about self-competence, ${ }^{35}$ the value placed on the students' selflessness ${ }^{31}$ among many others. In response, the student can show signs of distress, such as depression, suicidal thoughts and burnout. ${ }^{29} 3233$ Better resilience levels protect against these negative responses and drive the student to act more ethically and responsibly, ${ }^{34}$ in addition to taking better care of himself or herself and others. ${ }^{35}$ 
Table 3 Proportions and ORs with Cls for resilience according to health variables

\begin{tabular}{|c|c|c|c|c|c|c|}
\hline & \multicolumn{4}{|c|}{ Resilience } & \multirow{2}{*}{$\begin{array}{l}\text { Moderate resilience } \\
\text { OR }(95 \% \mathrm{Cl})\end{array}$} & \multirow{2}{*}{$\begin{array}{l}\text { High resilience } \\
\text { OR }(95 \% \mathrm{Cl})\end{array}$} \\
\hline & $\mathbf{N}$ & \%low & $\%$ moderate & \%high & & \\
\hline \multicolumn{7}{|c|}{ Perception of one's own health* } \\
\hline Good & 252 & 39.7 & 42.5 & 17.8 & $1.9(1.1$ to 3.4$)$ & 2.5 (1.1 to 5.8$)$ \\
\hline Very good & 211 & 27.5 & 37.4 & 35.1 & 2.5 (1.4 to 4.5$)$ & 7.1 (3.1 to 16.2$)$ \\
\hline \multicolumn{7}{|l|}{ Smoking habits } \\
\hline Never smoked & 491 & 36.9 & 39.3 & 23.8 & & \\
\hline $\begin{array}{l}\text { Former smoker } \\
\text { or current smoker }\end{array}$ & 51 & 43.1 & 37.3 & 19.6 & $0.8(0.4$ to 1.5$)$ & 0.7 (0.3 to 1.5$)$ \\
\hline \multicolumn{7}{|l|}{ 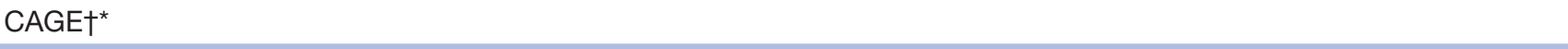 } \\
\hline No & 452 & 35 & 40.9 & 24.1 & & \\
\hline Used in the past & 79 & 55.7 & 30.4 & 13.9 & 0.5 (0.3 to 0.8$)$ & $0.3(0.2$ to 0.7$)$ \\
\hline \multicolumn{7}{|l|}{ Use of illegal drugs§ } \\
\hline Never used & 379 & 36.2 & 40.1 & 23.7 & & \\
\hline Used in the past & 147 & 40.1 & 38.1 & 21.8 & 0.9 (0.6 to 1.3$)$ & 0.8 (0.5 to 1.4$)$ \\
\hline
\end{tabular}

reference category: low resilience.

*p Value $<0.2$.

†CAGE questionnaire with the purpose of identifying disorders caused by alcohol abuse, rendered positive by two affirmative answers.

$\ddagger$ Prescription drugs: used of habit-forming medications.

§lllegal drugs: marijuana, cocaine and crack.

There has been interest in better understanding resilience in these students precisely due to the many factors to which they are exposed during an important period of their lives, specifically the undergraduate programme in medicine, and the many important changes they experience.

The assumption was that resilience in women would be higher due to the explicit and implicit barriers that they must continuously overcome. A greater sensitivity and the ability to better process feelings are characteristics that define the female profile. In contrast to this assumption, the present findings corroborated other studies, some involving medical students, ${ }^{10}$ that found no association between gender and resilience. ${ }^{16214244}$ However, other studies have shown higher resilience in women, such as a study conducted among health professionals in England. ${ }^{40}$ And others still have shown the contrary,

\begin{tabular}{lccccl}
\hline Table 4 & \multicolumn{5}{c}{ Multivariate model* $^{*}$ for resilience } \\
\hline OR & SD & $\mathbf{Z}$ & $\mathbf{p}>\mathbf{z}$ & $95 \% \mathbf{C l}$ \\
Health & 0.57 & 0.69 & -4.61 & 0.00 & 0.45 to 0.73 \\
Age & 1.37 & 0.14 & 3.12 & 0.00 & 1.12 to 1.67 \\
Medicationst & 0.58 & 0.10 & -3.21 & 0.00 & 0.41 to 0.80 \\
\hline
\end{tabular}

*Table shows only the variables with statistical significance.

†Habit-forming medications. such as the higher resilience rates found in male Chinese medical students and Italian youngsters. ${ }^{11} 45$

In light of the meagre number of black and mixed-race individuals among medical students in Brazil, this group represents a minority within this context, even though it represents $50.2 \%$ of the Brazilian population. ${ }^{46}$ This difference is likely justified by the fact that the white population is still economically affluent and, therefore, it has better access to the course of medicine. In this census, however, the proportion of future black and mixed-race doctors $(40.7 \%)$ was higher than at other schools because the captioned institution has adopted a quota system of admissions since 2003. Although the literature suggests higher resilience among groups that are considered minorities, ${ }^{12}$ precisely because they have to break down barriers and face greater adversity from a young age, no such difference in resilience was found in this study.

Similarly to other studies, in this study, no association was found between sociodemographic variables and resilience, with the exception of age. In this study, according to the census, age contributes to the resilience level: the older the participant, the more resilient. Although a Brazilian article has been produced that found no variance in resilience based on the year of the programme, ${ }^{10}$ that is to say, that resilience is no higher in older students, the results of this study were similar to the majority of the 
existing studies, ${ }^{12} 274142$ including one focusing on health professionals. ${ }^{40}$

As the existing literature indicates, medical students ${ }^{47}$ mature over time, as they are repeatedly exposed to difficult situations. In the two final years, the students spend most of their time in the company of residents and teachers. Indications show that disciplined association, structured on partnership, within an ethical environment, boosts students' resilience. ${ }^{47}$ The researchers believe that the students evaluated feel a sense of belonging to such positive environments and this, combined with the repeated exposures resulting from their activity profile, contribute to the building of resilience during the clerkship period.

In the analyses conducted here, students who lived alone showed no difference in resilience as compared with students with different living situations. A possible explanation for this is that living alone does not mean that the student does not feel protected by a support system outside the current living situation. This might also account for the similarity with other groups studied, involving children ${ }^{19}$ and elderly individuals ${ }^{48}$ from developed countries, described in prior studies.

It is a common belief that a good income level is associated with material and emotional well-being. Having money can resemble protection due to the access it affords to good schools, good medical care and peace of mind in old age. The variables related to income were represented in this study by the type of school attended before, by whether the student is financially independent, by the parents' education level and whether the student was admitted as a result of a quota system.

In Brazil, public schools are usually attended by the low-income population, while medical students medical students come mostly from private schools, and are mostly supported financially by their families, and so a direct association exists between a better education level of the parents and higher income, on the other hand, the students in the quota system are directly or indirectly associated with low income. This study found, as did the existing literature examined, ${ }^{19} 2041$ that the variables related to income show no association with resilience. This is a very interesting conclusion as it forces us to consider the possibility that personal or collective attitudes or approaches could be capable of boosting resilience and so improving people's lives in different ways, regardless of each person's financial possibilities.

At first glance, the association between resilience and religion may seem relevant. The WHO uses faith as a quality of life ${ }^{49}$ indicator, which implies that having a faith can increase the quality of life. In addition, religion is known to promote well-being, which might indicate that religious individuals are more resilient due to the sense of protection that they experience. ${ }^{612}$ However, this study found no association between these variables. This may be due to the fact that the instrument was used to measure the individual's choice to embrace a religion and not the person's religiousness or belief in its essence.
The questionnaire used in this study made no distinction between self-prescribed use of habit-forming drugs and their as part of a treatment under medical supervision, which could be construed as a limitation of the study. At any rate, the census's findings show that the vast majority of the students studied do not use such medications, which differs from the findings of another study on Brazilian medical students. ${ }^{50}$ However, awareness of the risks of this practice and the unnecessary use of these substances makes their consumption less likely among individuals with greater resilience.

It is not hard to believe that resilience might act as a protective factor against smoking and alcoholism, as previously noted in studies on different populations: middle-aged Spanish women, ${ }^{18}$ Turkish youngsters ${ }^{26}$ and American war veterans. ${ }^{51}$ Understanding how damaging those substances are to health might encourage more resilient individuals to avoid those addictions, ${ }^{52}$ confirming the association found between the non-use of habit-forming medications and high resilience. Alternately, high resilience could reduce substance abuse in response to stress and mental suffering.

In this study, suspected alcohol abuse, which was identified using the CAGE questionnaire, showed a reverse association with resilience levels in the bivariate analysis. However, when controlled in terms of other variables, this variable lost its effect and was useless in identifying vulnerable groups. Presumably, the effect of high resilience on preventing the use of habit-forming medications minimised the effect of alcohol dependence in the multivariate analysis.

The responding students described their perception of their own health. The literature indicates, supported by highly reliable data, that self-assessments are capable of conveying additional knowledge that might not be fully determined through epidemiological clinical measurements or any other available measurements. For some reason, which has yet to be fully understood, the individual has a knowledge of the self that he or she is not even aware of. ${ }^{53}$

The findings of this study showed an important association between high resilience and a good perception of one's own health. At the same time, a number of articles show that increased resilience promotes better self-care among HIV-positive patients, ${ }^{54}$ protects against depression among prison workers ${ }^{55}$ and helps the partners of patients with prostate cancer to better cope with the disease. ${ }^{56}$

It is also believed that working on building resilience is an important tool to encourage the practice of sports and healthier eating habits, ${ }^{9}$ to dissuade youngsters from engaging in sexual promiscuity ${ }^{23}$ and allow them to benefit from an overall improvement to their health. ${ }^{19} 57$

The limited causality established in this study, due to fact that it is a cross-sectional survey, is more strongly reflected in the variables concerning health behaviour, such as: is the individual more resilient because he or she takes better care of him or herself or does he or she takes 
better care of him or herself because he or she is more resilient?

Please note that the study population, namely medical students who work with health/disease and medicalisation/non-medicalisation, tends to have as the variables most closely associated to resilience two aspects falling within their core values: health and medication. This raises the following question: is resilience influenced, primarily, by the specific values tied to each populational group? Would it be appropriate to extend the results to other realities? Additional studies would have to be conducted with other populations in order to confirm this association. A better understanding of this possibility might be useful in devising specific actions to boost resilience within the various groups. Or should we pursue other explanations for these findings?

In past years, genetic issues have been found to be associated with resilience, which shows that it might be mediated by adaptive changes to a number of neural circuits involving several neurotransmitters and molecular pathways. ${ }^{58}$ There is still much to be understood about this, but we believe that it is important to reflect on the likely relevance of these individual variances impacting the temperament traits and character traits. ${ }^{59} 60$

So, by association, does a better state of health or better conditions exist to prevent students from feeling the need to resort to the use of habit-forming drugs before medical school? It is a known fact that those students are, in their majority, resilient and, in turn, those who are most resilient possess temperament features, such as reward dependence and persistence, and character traits, such as self-directedness and cooperativeness. ${ }^{59}$ These findings have been repeated in another study involving physicians. ${ }^{60}$ Should we be allowed to speculate that it is precisely because they possess these qualities that medical students choose to take the course and that the associations found between high resilience, a good perception of one's own health and the non-use of habit-forming drugs are simply a consequence of this?

Resilience has received growing attention in recent years due to the finding that strategies to boost resilience could be positive, transformative measures from the individual and collective viewpoints.

This article discusses certain characteristics of medical students and shows that being older, having a good perception of one's health and refraining from using habit-forming medications are associated with increased resilience. However, variables concerning income and religion were not associated with resilience.

Acknowledgements We would like to thank Professor Sandra Fortes for her comments on the final text.

Contributors ACPd0: substantial contributions to the conception and design of the work; analysis and interpretation of data for the work; drafting the work and revising it critically for important intellectual content; final approval of the version to be published; agreement to be accountable for all aspects of the work in ensuring that questions related to the accuracy or integrity of any part of the work are appropriately investigated and resolved. RNA: substantial contributions to the conception and design of the work; the acquisition, analysis and interpretation of data for the work; revising the work critically for important intellectual content; final approval of the version to be published; agreement to be accountable for all aspects of the work in ensuring that questions related to the accuracy and integrity of any part of the work are appropriately investigated and resolved. APGM: substantial contributions to the conception and design of the work; the acquisition of data for the work; revising the work critically for important intellectual content; final approval of the version to be published; agreement to be accountable for all aspects of the work in ensuring that questions related to the accuracy and integrity of any part of the work are appropriately investigated and resolved.

Competing interests None declared.

Patient consent Obtained.

Ethics approval Ethics Committee in Research of Universidade Estadual do Rio de Janeiro, Rio de Janeiro, Brazil, according to Law nº196 of 10 October 1996.

Provenance and peer review Not commissioned; externally peer reviewed.

Data sharing statement We shall make data available to the scientific community with as few restrictions as feasible, while retaining exclusive use until the publication of major outputs. All available data can be obtained by contacting the corresponding author.

Open Access This is an Open Access article distributed in accordance with the Creative Commons Attribution Non Commercial (CC BY-NC 4.0) license, which permits others to distribute, remix, adapt, build upon this work non-commercially, and license their derivative works on different terms, provided the original work is properly cited and the use is non-commercial. See: http://creativecommons.org/ licenses/by-nc/4.0/

(C) Article author(s) (or their employer(s) unless otherwise stated in the text of the article) 2017. All rights reserved. No commercial use is permitted unless otherwise expressly granted.

\section{REFERENCES}

1. Rutter M. Resilience concepts and findings: implications for family therapy. J Fam Ther 1999;21:119-44.

2. Walsh F. The concept of family resilience: crisis and challenge. Fam Process 1996;35:261-81.

3. Egeland B, Carlson E, Sroufe LA. Resilience as process. Dev Psychopathol 1993;5:517-28.

4. Gartland D, Bond L, Olsson CA, et al. Development of a multidimensional measure of resilience in adolescents: the Adolescent Resilience Questionnaire. BMC Med Res Methodol 2011;11:134-43.

5. Masten AS. Ordinary magic. Resilience processes in development. Am Psychol 2001;56:227-38.

6. Werner EE. Risk, resilience, and recovery: perspectives from the Kauai Longitudinal study. Dev Psychopathol 1993;5:503-15.

7. Zimmerman MA, Arunkumar R. Resiliency research: implications for schools and policy. Social Policy Report 1994;8:1-17.

8. Bentley M. An ecological public health approach to understanding the relationships between sustainable urban environments, public health and social equity. Health Promot Int 2014;29:528-37.

9. Bergh $\mathrm{C}$, Udumyan $\mathrm{R}$, Fall $\mathrm{K}$, et al. Stress resilience and physical fitness in adolescence and risk of coronary heart disease in middle age. Heart 2015;101:623-9.

10. Tempski P, Santos IS, Mayer FB, et al. Relationship among medical student resilience, educational environment and quality of life. PLoS One 2015;10:e0131535.

11. Stratta P, Capanna C, Patriarca S, et al. Resilience in adolescence: Gender differences two years after the earthquake of L'Aquila. Pers Individ Dif 2013;54:327-31.

12. Dyrbye LN, Power DV, Massie FS, et al. Factors associated with resilience to and recovery from burnout: a prospective, multi-institutional study of US medical students. Med Educ 2010;44:1016-26.

13. Kjeldstadli K, Tyssen R, Finset $A$, et al. Life satisfaction and resilience in medical school--a six-year longitudinal, nationwide and comparative study. BMC Med Educ 2006;6:1.

14. Williams J, Hadjistavropoulos T, Ghandehari OO, et al. Resilience and organisational empowerment among long-term care nurses: effects on patient care and absenteeism. J Nurs Manag 2016;24:300-8.

15. Goodyear HM. First year doctors experience of work related wellbeing and implications for educational provision. Int J Med Educ 2014;5:103-9.

16. Petrowski K, Brähler E, Zenger M. The relationship of parental rearing behavior and resilience as well as psychological symptoms in a representative sample. Health Qual Life Outcomes 2014;12:95. 
17. Rozemberg L, Avanci J, Schenker M, et al. Resiliência, gênero e família na adolescência/Resilience, gender and family during adolescence. Ciênc Saude Coletiva 2014;19:673-84.

18. Coronado PJ, Oliva A, Fasero M, et al. Resilience and related factors in urban, mid-aged Spanish women. Climacteric 2015;18:867-72.

19. Perna L, Mielck A, Lacruz ME, et al. Socioeconomic position, resilience, and health behaviour among elderly people. Int $J$ Public Health 2012;57:341-9.

20. Richards L. For whom money matters less: social connectedness as a resilience resource in the UK. Soc Indic Res 2016;125:509-35.

21. Morano C. Resilience and coping with trauma: does gender make a difference? J Hum Behav Soc Environ 2010;20:553-68.

22. Walker SN, Sechrist KR, Pender NJ. The health-promoting lifestyle profile: development and psychometric characteristics. Nurs Res 1987;36:76-81.

23. Oppong Asante K, Meyer Weitz A. International note: association between perceived resilience and health risk behaviours in homeless youth. J Adolesc 2015;39:36-9.

24. Stoddard SA, Whiteside L, Zimmerman MA, et al. The relationship between cumulative risk and promotive factors and violent behavior among urban adolescents. Am J Community Psychol 2013;51:57-65.

25. Mistry R, McCarthy WJ, Yancey AK, et al. Resilience and patterns of health risk behaviors in California adolescents. Prev Med 2009;48:291-7.

26. Altay N, Toruner EK, Citak EA. Determination of smoking and drinking and preventive measures in adolescents. J Addict Nurs 2014;25:94-102.

27. Lamond AJ, Depp CA, Allison M, et al. Measurement and predictors of resilience among community-dwelling older women. J Psychiatr Res 2008;43:148-54.

28. Finan $\mathrm{PH}$, Garland EL. The role of positive affect in pain and its treatment. Clin J Pain 2015;31:177-87.

29. Dahlin M, Joneborg N, Runeson B. Stress and depression among medical students: a cross-sectional study. Med Educ 2005;39:594-604.

30. Sreeramareddy CT, Shankar PR, Binu VS, et al. Psychological morbidity, sources of stress and coping strategies among undergraduate medical students of Nepal. BMC Med Educ 2007;7:26-33.

31. Dyrbye L, Shanafelt T. Nurturing resiliency in medical trainees. Med Educ 2012;46:343-8.

32. Dyrbye LN, Thomas MR, Huntington JL, et al. Personal life events and medical student burnout: a multicenter study. Acad Med 2006;81:374-84.

33. Dyrbye LN, Thomas MR, Massie FS, et al. Burnout and suicidal ideation among U.S. medical students. Ann Intern Med 2008;149:334-41.

34. Tempski P, Martins MA, Paro HB. Teaching and learning resilience: a new agenda in medical education. Med Educ 2012;46:345-6.

35. Gentile JP, Roman B. Medical student mental health services: psychiatrists treating medical students. Psychiatry(Edgemont) 2009;6:38-45.

36. Wagnild GM, Young HM. Development and psychometric evaluation of the Resilience Scale. J Nurs Meas 1993;1:165-78.

37. Mayfield D, McLeod G, Hall P. The CAGE questionnaire: validation of a new alcoholism screening instrument. Am J Psychiatry 1974;131:1121-3.

38. Pesce RP, Assis SG, Avanci JQ, et al. Adaptação transcultural, confiabilidade e validade da escala de resiliência [Cross-cultural adaptation, reliability and validity of the resilience scale]. Cad Saúde Pública 2005;21:436-48.

39. Losoi H, Turunen S, Wäljas M, et al. Psychometric properties of the finnish version of the resilience scale and its short version. Psychology, Community \& Health 2013;2:1-10.

40. Sull A, Harland N, Moore A. Resilience of health-care workers in the UK; a cross-sectional survey. J Occup Med Toxicol 2005:10-11.
41. Wagnild G. Resilience and successful aging. Comparison among low and high income older adults. J Gerontol Nurs 2003;29:42-9.

42. Lundman B, Strandberg G, Eisemann M, et al. Psychometric properties of the Swedish version of the Resilience Scale. Scand J Caring Sci 2007;21:229-37.

43. Erogul M, Singer G, Mclntyre T, Mclnture SDG, et al. Abridged mindfulness intervention to support wellness in first-year medical students. Teach Learn Med 2014;26:350-6.

44. Lopes VR, Martins MC. Validaçãofatorial da escala de resiliência de Connor-Davidson (Cd-Risc-10)para brasileiros [Factorial Validation and Adaptation of theConnor-Davidson Resilience Scale (CdRisc-10) for Brazilians]. Rev Psicol 2011;11:36-50.

45. Peng L, Zhang J, Li M, et al. Negative life events and mental health of Chinese medical students: the effect of resilience, personality and social support. Psychiatry Res 2012;196:138-41.

46. Online Document Demográfico C. Instituto brasileiro de geografia e estatística [Brazilian Institute of Geography and Statistics]]. Rio de Janeiro: IBGE, 2010. http://www.ibge.gov.br/home/estatistica/ populacao/censo2010/ (accessed 20 Mar 2016).

47. Haglund ME, aan het Rot M, Cooper NS, et al. Resilience in the third year of medical school: a prospective study of the associations between stressful events occurring during clinical rotations and student well-being. Acad Med 2009;84:258-68.

48. Lueger Schuster B, Weind D, Kantor V, et al. Resilience and mental health in adult survivors of child abuse associated with the institution of the Austrian Catholic Church. J Trauma Stress 2014;27:568-75.

49. Leplege A, Ecosse E. Methodological issues in using the Rasch model to select cross culturally equivalent items in order to develop a quality of life index: the analysis of four WHOQOL-100 data sets (Argentina, France, Hong Kong, United Kingdom). J App/Meas 2000;1:372-92.

50. Da Silveira DX, Rosa Oliveira L, Di Pietro M, et al. Evolutional pattern of drug use by medical students. Addict Behav 2008;33:490-5.

51. Green KT, Beckham JC, Youssef N, et al. Alcohol misuse and psychological resilience among U.S. Iraq and Afghanistan era veterans. Addict Behav 2014;39:406-13.

52. Dillon L, Chivite-Matthews N, Grewal I, et al. Risk, protective factors and resilience to drug use: identifying resilient young people and learning from their experiences. London, UK: Home Office Online Report, 2007

53. Mavaddat N, Parker RA, Sanderson S, et al. Relationship of selfrated health with fatal and non-fatal outcomes in cardiovascular disease: a systematic review and meta-analysis. PLoS One 2014;9:e103509.

54. Herrick AL, Stall R, Chmiel JS, et al. It gets better: resolution of internalized homophobia over time and associations with positive health outcomes among MSM. AIDS Behav 2013;17:1423-30.

55. Liu L, Hu S, Wang L, et al. Positive resources for combating depressive symptoms among Chinese male correctional officers: perceived organizational support and psychological capital. BMC Psychiatry 2013;13:13:1

56. Lim JW, Shon EJ, Paek M, et al. The dyadic effects of coping and resilience on psychological distress for cancer survivor couples. Support Care Cancer 2014;22:3209-17.

57. Nagata JM, Fiorella KJ, Salmen CR, et al. Around the table: food insecurity, socioeconomic status, and instrumental social support among women living in a rural Kenyan island community. Ecol Food Nutr 2015;54:358-69.

58. Feder A, Nestler EJ, Charney DS. Psychobiology and molecular genetics of resilience. Nat Rev Neurosci 2009;10:446-57.

59. Eley DS, Leung J, Hong BA, et al. Identifyimg the dominant personality profiles in medical students: implications for their wellbeing and resilience. PLoS One 2016;11:e0160028.

60. Eley DS, Cloninger CR, Walters L, et al. The relationship between resilience and personality traits in doctors: implications for enhancing well being. PeerJ 2013;1:e216. 